\title{
Contextual control of first- and second-learned excitation and inhibition in equally ambiguous stimuli
}

\author{
JAMES BYRON NELSON \\ Universidad de Pais Vasco, San Sebastian, Spain
}

\begin{abstract}
In two three-phase experiments, rats received a final third excitatory (Experiment 1) or inhibitory (Experiment 2) phase of conditioning with a tone. The third phase came immediately prior to a test with the tone, either in the context where the tone was trained or in a different context. Groups differed in each experiment with respect to the first two phases. Rats in Groups EIE (Experiment 1) and EII (Experiment 2) received excitatory conditioning with the tone in Phase 1, followed by inhibitory conditioning with the tone. Rats in Groups IEE (Experiment 1) and IEI (Experiment 2) received inhibitory conditioning in Phase 1, followed by excitatory conditioning in Phase 2. Thus, the association being expressed in Phase 3 was consistent either with what was learned first about the stimuli or with what was learned second. Contrary to expectations, the association being expressed at the end of Phase 3, either excitatory or inhibitory, was affected by a context change, regardless of its consistency with what was learned first about the CS.
\end{abstract}

The term "renewal" typically refers to the recovery of a previously extinguished conditioned response (CR) induced by a change in the background context where extinction took place. The effect was demonstrated by Bouton and Bolles (1979) and has remained a topic of considerable interest over the last three decades, attracting the attention of clinical researchers through its similarity and relevance to situations in which clinical relapse occurs (e.g., Bouton, Mineka, \& Barlow, 2001; Mineka, Mystkowski, Hladek, \& Rodriguez, 1999).

The predominant explanation for renewal is that offered by Bouton (1993, 1994a, 1994b, 1997), according to whom an internal representation of a conditioned stimulus (CS) enters into an excitatory association during conditioning with a representation of the unconditioned stimulus (US); activation of the US representation by way of that association results in the CR. This mechanism is diagrammed as Link 1 in Figure 1 (Bouton \& Nelson, 1994). The diagram is meant to illustrate the relative independence of such an association from other stimuli (e.g., the context) in its ability to activate the US representation, thus operating across different settings (e.g., Bouton \& King, 1983; Havermans, Keuker, Lataster, \& Jansen, 2005; Kaye \& Mackintosh, 1990; Nelson \& Bouton, 1997). The mechanism is not meant to imply that simple excitatory responding is completely unaffected by a context change. Changes in context after simple excitatory conditioning can produce decrements in responding (e.g., Bonardi, Honey, \& Hall, 1990; Hall \& Honey, 1989, 1990; Honey, Willis, \& Hall, 1990), but robust transfer appears to be the case more often than not.
Bouton assumed that extinction involves the acquisition of an inhibitory association between the relevant centers (e.g., Wagner, 1981). In this way, the CS can be described as becoming ambiguous (Bouton, 1993), in that it can simultaneously both activate and suppress the US representation. The context was assumed to become important in extinction. The mechanism representing this importance is diagrammed as Links 2.1-2.3 in Figure 1. The secondlearned inhibitory association acquired in extinction is assumed to be gated (e.g., Estes, 1976), in that input from the CS and from the context in which the inhibition was acquired is necessary for activation. It is through this gating mechanism that the context disambiguates a conditioned and extinguished CS.

Bouton (1993) made two assumptions about why learning in extinction results in the pathways represented by the Link-2 mechanisms. First, he assumed that inhibitory learning was a form of learning that was inherently sensitive to context. Second, he suggested that when a CS acquires a new meaning, as during extinction, the context becomes important and gains control of the resulting learning, perhaps through an attention mechanism (Bouton, 1997). Evidence confirming the first of these suggestions has yet to be obtained. Both Bouton and Nelson (1994) and Nelson and Bouton (1997) have demonstrated that inhibition conditioned to a stimulus in a traditional conditioned inhibition design transfers without loss across contexts.

Evidence in favor of the second assumption has been produced by Nelson (2002). In those studies excitatory and inhibitory associations were conditioned to a tone CS by pairing the tone with food $(\mathrm{T}+)$, or by using the 


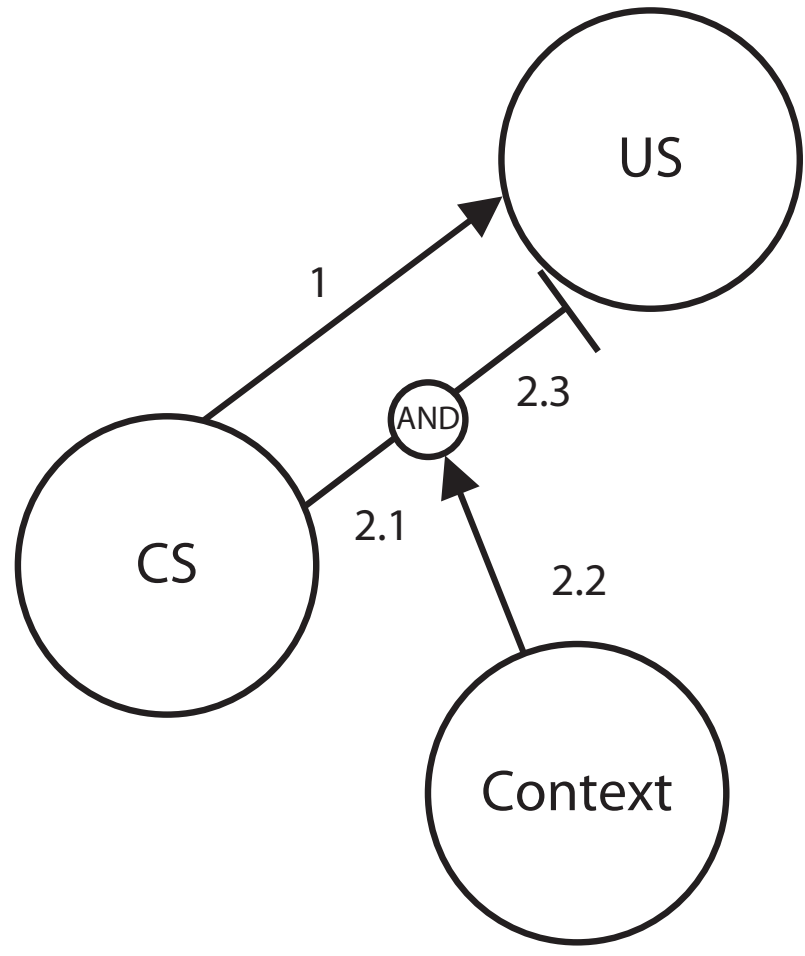

Figure 1. Model of learning in conditioning and extinction. Arrows (Links 1, 2.1, and 2.2) indicate excitatory associations; blocked lines (2.3) indicate inhibition. The model shows that first-learned excitatory associations are relatively independent of context, whereas second-learned associations, such as inhibition acquired in extinction, are more dependent on context. Activation of second-learned inhibition depends on input from the conditioned stimulus (CS) and the context in which it was acquired. US, unconditioned stimulus.

tone as the inhibitory feature in a $\mathrm{D}+/ \mathrm{TD}-$ conditioned inhibition discrimination, where darkness $(\mathrm{D}$, the offset of the houselights) was paired with food but not when accompanied by the tone. In one experiment, the experimental group first received inhibitory conditioning with the tone, followed by a phase of excitatory conditioning. Control conditions either received the tone paired with food throughout the phases of training, or received no exposure to the tone whatsoever in the first phase. Thus, for the experimental group the excitatory association was the second of two learned associations, but the first and only association in the control groups. When the tone was presented in a different context, there was a loss in the experimental group of the excitatory association; this did not occur in the control conditions. An excitatory tone-food association, ordinarily insensitive to a context change with this method (e.g., Nelson, 2002; Nelson \& Bouton, 1997), became more sensitive when it was the second association acquired to the CS. In a second experiment, the phases were reversed so that the target CS was inhibitory at the time of testing and the analogous result was obtained. The results showed that inhibition conditioned to the CS was more sensitive to context change when it was the second association acquired to the CS.
The present experiments were designed to conceptually replicate and extend those of Nelson (2002). In those experiments the experimental groups differed from the controls in two ways: The association assessed in the test phase was the second learned, and the CS was ambiguous. The association being expressed at the time of test was the same in both conditions, but the CS in the experimental groups could be considered ambiguous in that it theoretically controlled two associations, whereas the CS in the control groups controlled only one. The present experiments addressed this confound by creating experimental and control groups for which the target CS was ambiguous in both conditions, with a manipulation of only the order in which the associations were acquired.

\section{EXPERIMENT 1}

The design of this experiment is shown in the top portion of Figure 2. The experiment was designed to assess the impact of a context change on an excitatory tone $\rightarrow$ food association in an ambiguous CS when that association was either the first or second learned. In an appetitive conditioning procedure, two groups received three phases of training ending in the third phase of excitatory conditioning with the tone. The groups differed with respect to the first two phases. Group IEE (Inhibition-ExcitationExcitation) received a phase of inhibitory conditioning with the tone where it was involved in an L (light)+/LT conditioned inhibition design, followed by two phases of excitatory conditioning where the tone was paired with food. Group EIE (Excitation-Inhibition-Excitation) first received a phase of excitatory conditioning with the tone and food, followed by inhibitory conditioning, as in the first phase for Group IEE. At the end of Phase 3, both groups had received exactly the same amounts of excitatory and inhibitory conditioning and the tone was a net excitor at the time of test. Thus, the experiment compared the sensitivity of an excitatory association with a context change when it was first or second learned in equally ambiguous stimuli. The experiment was conducted with replication.

From the simple perspective put forth by Nelson (2002), that second-learned associations are more contextually controlled than those learned first, there should be a larger effect of a context change in Group IEE than in Group EIE. In Group IEE, where excitation was a secondlearned association, there should be less responding to tone stimulus $(\mathrm{T})$ when present in a new context. There should be little effect of a change in context in Group EIE, where excitation was a first-learned association.

\section{Method}

\section{Subjects}

Sixteen female Wistar rats were used in each replication, with 8 randomly assigned to each condition. Rats were housed in stainless steel hanging cages on a 12:12-h light:dark cycle. The experiment was conducted in the light part of the cycle. Water was available ad lib. Access to food was restricted, as described below.

\section{Apparatus}

All experimental equipment was contained in sound attenuation chambers. Each chamber measured $54 \times 39 \mathrm{~cm}$. A $12.5-\mathrm{cm} 8-\Omega$ 


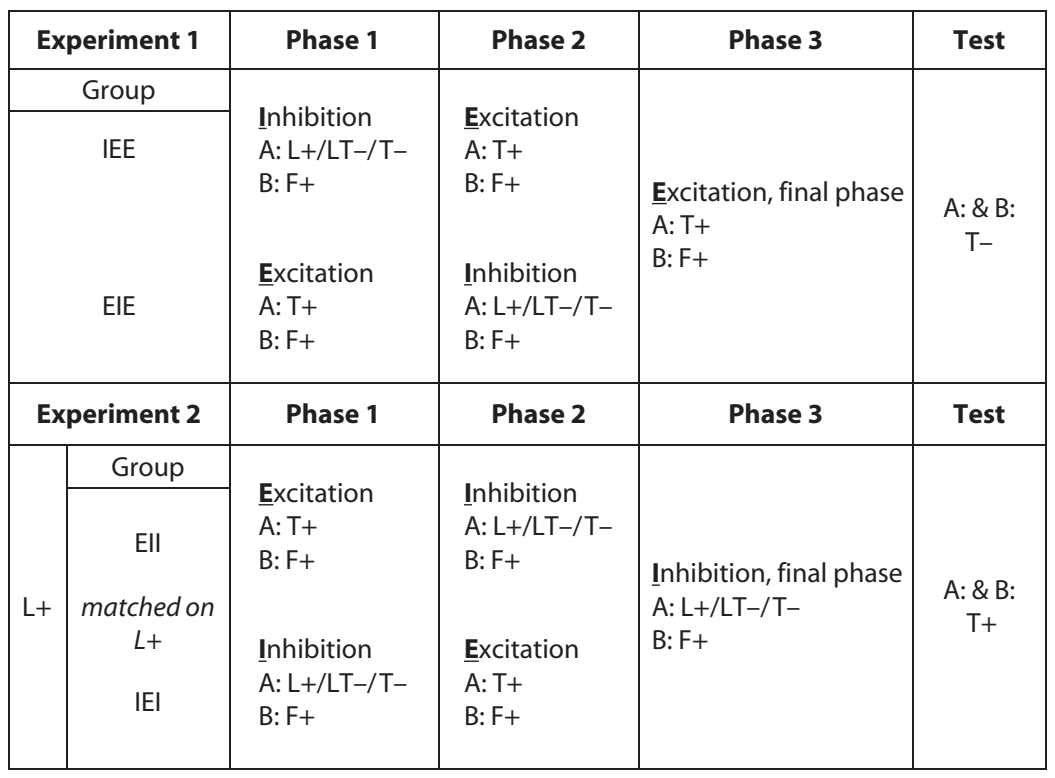

Figure 2. Design of experiments. A: and B: are contexts. T, 3000-Hz tone; L, keylight; F, flashing LEDs; +, food pellet, unconditioned stimulus (US); -, no US; / indicates intermixed trials within sessions. Groups were randomly assigned in Experiment 1. Groups were matched on four sessions of $L+$ conditioning in Experiment 2.

speaker was mounted on the right wall at a height of $34 \mathrm{~cm}$ and $18 \mathrm{~cm}$ from the rear wall. A $12-\mathrm{V}$ light was mounted in the ceiling of the chamber in a $12 \times 6 \times 3 \mathrm{~cm}$ plastic diffusing prism. The prism was mounted with the length parallel to the rear wall, $18 \mathrm{~cm}$ from the rear wall and $10 \mathrm{~cm}$ from the right wall. Mounted in the lower left corner of each chamber was a $7.5-\mathrm{cm}$ square ventilation fan that provided $60 \mathrm{~dB}$ of background noise.

Subjects were run in eight standard operant testing boxes (MED Associates ENV-007). Each box was placed in an attenuation chamber $18 \mathrm{~cm}$ from the right wall and $8 \mathrm{~cm}$ from the rear wall, so that the right panel of the boxes, which contained the stimulus lights, was in shadow.

The front, back, and top of each $30.5 \times 24.1 \times 29.2$-cm box was Plexiglas, with the right and left walls constructed of aluminum. The grid floors had bars of $3 \mathrm{~mm}$, spaced $1 \mathrm{~cm}$ apart. The right wall of each box contained nonauditory stimuli. A food delivery magazine with a $5 \times 5-\mathrm{cm}$ square opening and a depth of $4 \mathrm{~cm}$ was centered from left to right in the wall and mounted so that the food trough was $5 \mathrm{~cm}$ above the grid floor. A photocell was mounted $1 \mathrm{~mm}$ above the trough at a depth of $1 \mathrm{~cm}$. Two white $28-\mathrm{V}$ keylights $(2.5-\mathrm{cm}$ diameter) were mounted $18 \mathrm{~cm}$ above the grid floor and $7 \mathrm{~cm}$ horizontally to the left and right of the center of the wall. Four centimeters above the food magazine, three 5-mm LEDs were mounted, with the second centered in the wall from left to right, and the other two mounted $1 \mathrm{~cm}$ to the left or right of the center. The leftmost LED was red, the center yellow, and the rightmost LED was green.

T was the delivery of an $80-\mathrm{dB}, 3000-\mathrm{Hz}$ tone through the speaker. The illumination of the keylight mounted to the left of the food cup served as Stimulus L. Each LED could be illuminated in turn from left to right in a flashing sequence. For example, the first LED was illuminated for a brief $20 \mathrm{msec}$, producing a flash. As that LED was turned off, the middle LED was flashed on, and so on, with the illumination of the leftmost LED following that of the rightmost LED. This flashing sequence of LEDs served as Stimulus F. All stimuli were $30 \mathrm{sec}$ in duration. When delivered, the US was the delivery of two 45-mg PJ Noyes pellets, Formula I, immediately on termination of the CS.

The eight operant boxes were divided into two sets of four to serve as Contexts A and B, and were always completely counterbalanced.
One set of boxes had a laminated solid-white sheet of paper located behind the rear Plexiglas wall so that it appeared uniformly white. The bars in the floor of these boxes were mounted parallel to each other at the same height. A $7.5 \times 5 \mathrm{~cm}$ cup containing $5 \mathrm{cl}$ of McCormick vanilla extract was placed outside the right wall of the operant chamber to the left of the food magazine. The other set of four boxes differed from the first in visual, tactile, and olfactory respects. The sheet of paper mounted outside the rear wall had a checkerboard pattern of $2.5-\mathrm{cm}$ black and white squares. The grid floor consisted of staggered grids, with odd-numbered grids mounted $1 \mathrm{~cm}$ above the even-numbered grids; the dish outside the right wall contained Heinz dark vinegar.

All events were controlled by a $386 \mathrm{dx}$ IBM-compatible computer. The computer sampled the photocells in each box over 1,700 times/ sec.

\section{Procedure}

The experiment was conducted in two identical replications with 16 rats in each replication ( 8 per group). Both replications followed the procedure below. Rats were food-deprived over 1 week to $80 \%$ of their free-feeding weight and were maintained at that weight throughout the experiment. On the 1st day of training, the rats were placed in both sets of boxes for $30 \mathrm{~min}$ in each session. During the first $15 \mathrm{~min}$, they were allowed to explore the chambers undisturbed; during the last $15 \mathrm{~min}, 20$ single food pellets were delivered on a variable $45-\mathrm{sec}$ schedule, to train the rats to eat from the food cup at the sound of a pellet delivery.

The rats were then randomly divided into two groups. Each group received four 60 -min sessions of training each day for the remainder of the experiment. Throughout, there were two sessions in Context $\mathrm{A}$ and two in Context $\mathrm{B}$, to ensure equal familiarity with each context. Every session in Context B contained a pairing of $\mathrm{F}$ with the US at the same time into the session as that at which the US occurred in the corresponding session in Context A. The order of exposure was $\mathrm{ABAB}$ or BABA, varying across days. Each experimental phase began in Context A. The first session of each day of training began with Group EIE, followed by Group IEI, and continued to alternate across the day. 
There were three phases of training. The order in which the phases were encountered varied between groups. Group EIE began training with excitatory conditioning followed by inhibitory conditioning, and ended with excitatory conditioning, final phase. Group IEE began training with inhibitory conditioning followed by excitatory conditioning and ending with excitatory conditioning, final phase. Details of these phases are discussed next.

Excitatory conditioning. The first excitatory conditioning phase with the tone contained 12 pairings of $\mathrm{T}$ and US, with an intertrial interval (ITI) varying around a mean of $270 \mathrm{sec}(S D=131 \mathrm{sec})$, in each of the two daily sessions in Context A. There were 4 days of training in the first excitatory conditioning phase.

Inhibitory conditioning. The first 2 days (four sessions) of inhibitory conditioning consisted of 12 pairings of $\mathrm{L}$ with food in each of the two daily sessions in Context A. The ITI was variable $(M=$ $270 \mathrm{sec}, S D=131 \mathrm{sec})$. The next 7 days (14 sessions) contained 18 trials in each of the two sessions in Context A with a variable ITI $(M=170 \mathrm{sec}, S D=63 \mathrm{sec})$. Those trials were divided into 12 trials in which $\mathrm{T}$ and $\mathrm{L}$ were compounded and food was not presented. There were 4 trials in which $\mathrm{L}$ was paired with food, and 2 trials in which $\mathrm{T}$ was presented by itself, so that presentations of $\mathrm{T}$ without $\mathrm{L}$ were not restricted to the excitatory conditioning phases. Trials were randomly intermixed within each session, with the restriction that 1 of the $\mathrm{L}+$ trials was followed by an $\mathrm{L}+$ trial (so that not every reinforced trial was followed by a nonreinforced trial), and that the $2 \mathrm{~T}-$ trials never occurred in a row. The same sequences of trials within sessions were used in both replications.

Excitatory conditioning (final phase). During the final phase of excitatory conditioning, $\mathrm{T}$ was paired with food on each trial in both daily sessions in Context A. There were six trials per each of the six sessions in Context A, with a mean ITI of $540 \mathrm{sec}(S D=149 \mathrm{sec})$.

Testing. Following the last day of the final phase, rats received two tests, with $\mathrm{T}$ in extinction in each context; the order was $\mathrm{ABAB}$ for half of the rats in each group, and BABA for the other half. During each session of the test, $\mathrm{T}$ was presented six times in extinction in a 30-min session, with a variable ITI $(M=270 \mathrm{sec}, S D=125 \mathrm{sec})$ in the first replication.

Experiment 1 was intended to be run in two identical replications, but a programming error in the second replication added two trials to the tests. Where the error produced no confound, the test results for both replications are presented together; otherwise, the data from each replication are presented separately.

\section{Data and Analysis}

During both the $30-\mathrm{sec}$ CSs and the $30 \mathrm{sec}$ immediately prior to the CS (pre-CS), a computer recorded the number of times the photocell in the food cup was interrupted. During training, session means of responding during the CS and pre-CS for each stimulus were analyzed. Individual trials were analyzed during the test. All data were analyzed with a mixed factorial ANOVA. Simple effects were conducted using an ANOVA with error terms appropriately derived from the overall analysis using standard methods (see Howell, 1987). Degrees of freedom for simple effects were reduced using the procedure devised by Welch (1937) and Satterthwaite (1946) to compensate for the pooling of potentially heterogeneous variances.

In the analysis of responding in the CS, effect sizes were computed for the overall ANOVAs and the simple-effect tests. Effect sizes for the overall ANOVAs were calculated using $\eta_{\mathrm{p}}^{2}$. For simple-effect tests involving only two levels of the independent variable, Cohen's $d\left[\left(\bar{X}_{1}-\bar{X}_{2}\right) / \sqrt{S_{\text {pooled }}^{2}}\right]$ was calculated. The pooled variance in the equation was calculated using the respective variances of the variables being compared in the simple-effect analysis, regardless of whether the comparison was between or within subjects. In both cases, the statistic represents the visible size of the effect, given the directly observable and unadjusted variance in the population. Simple-effect tests were planned except where noted. Throughout, a rejection criterion of $p<.05$ was adopted, although exact probabilities were reported to provide a fuller characterization of the results.

\section{Results}

\section{Training}

Session means of responding to the stimuli during the training phases are shown in Figure 3. All training was exactly the same between replications; for simplicity's sake, replication was ignored in the analysis of the training data. Both replications showed the same pattern described by the overall analyses, although overall responding was somewhat higher in the second replication than in the first. Direct comparison between the two groups was confined to the final phase, in which they received training on the same task at the same time.

Analyses of the first two phases (leftmost panels of Figure 3) began with Group IEE (top panel) and followed Figure 3 from left to right. During the initial portion of the inhibitory conditioning phase, responding to $\mathrm{L}$ increased prior to the conditioned inhibition training $[F(3,45)=$ $\left.13.29, p<.001, \eta_{\mathrm{p}}^{2}=.47\right]$. The conditioned inhibition portion of inhibitory conditioning was analyzed with a stimulus $(\mathrm{L}, \mathrm{LT}, \mathrm{T}) \times$ session ANOVA. Responding to $\mathrm{L}$ continued to increase, but responding to $\mathrm{LT}$ and $\mathrm{T}$ decreased over the sessions, as indicated by a stimulus $\times$ session interaction $\left[F(26,390)=6.61, p<.001, \eta_{\mathrm{p}}^{2}=.31\right]$. Simple effects of session with each stimulus were all reliable $[F \mathrm{~s}(13,390) \geq$ $5.88, p \mathrm{~s}<.001]$. During excitatory conditioning, responding to $\mathrm{T}$ increased $\left[F(7,105)=19.07, p<.001, \eta_{\mathrm{p}}^{2}=.56\right]$.

In Group EIE, responding to $\mathrm{T}$ first increased during the excitatory conditioning phase $[F(7,105)=15.71, p<$ $\left..001, \eta_{\mathrm{p}}^{2}=.51\right]$. During the initial portion of the inhibitory conditioning phase, responding to $\mathrm{L}$ increased $[F(3,45)=$ $\left.13.17, p<.001, \eta_{\mathrm{p}}^{2}=.47\right]$. In the remainder of the inhibitory conditioning phase, responding to L continued to increase, but responding to LT and T decreased over sessions as indicated by a stimulus $\times$ session interaction $\left[F(26,390)=8.25, p<.001, \eta_{\mathrm{p}}^{2}=.36\right]$. Simple effects of session with each stimulus were reliable $\left[F_{\mathrm{s}}(13,390) \geq\right.$ $1.76, p \mathrm{~s} \leq .047]$.

Session means of responding to $\mathrm{T}$ during excitatory conditioning, final phase were compared between the groups and are shown in the rightmost panel of Figure 3. The data were analyzed with a group $\times$ session ANOVA, which showed a reliable group $X$ session interaction $\left[F(5,150)=22.27, p<.001, \eta_{\mathrm{p}}^{2}=.43\right]$. Simple effects of group at each session showed that the groups differed on the first three sessions $[F \mathrm{~s}(1,57) \geq 4.30, p \mathrm{~s} \leq .04$, $d \mathrm{~s} \geq .90]$, but not on the final three $\left(F_{\mathrm{s}} \leq 1.57\right)$.

Pre-CS response rates were analyzed during excitatory conditioning, final phase with a group $\times$ session ANOVA. The analysis showed a negligible effect of session $\left[F(5,150)=2.40, p=.04, \eta_{\mathrm{p}}^{2}=.07\right]$. Pre-CS responding increased from an average of 3.89 to 4.28 during this phase. There were no other reliable effects in the pre$\mathrm{CS}$ analysis $(F \mathrm{~s} \leq 1.71)$.

\section{Testing}

Replication 1. Data from the first replication are shown in the left-hand part of Figure 4. The six trials in each session of testing in each context were analyzed with a group $\times$ context $\times$ trials $\times$ session ANOVA. There were 


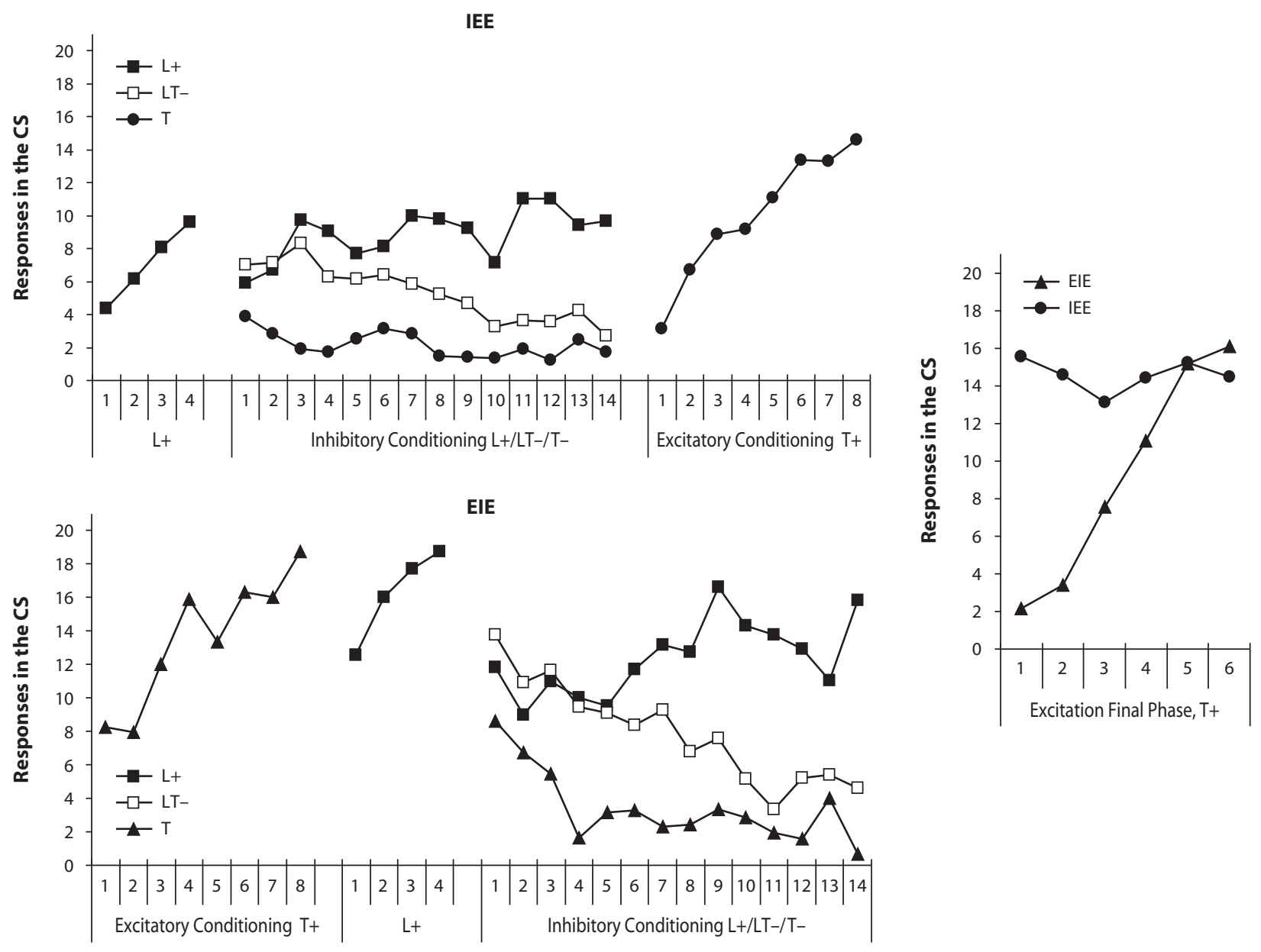

Figure 3. Results of excitatory and inhibitory conditioning with a tone conditioned stimulus (CS) from Experiment 1. Rats in Group IEE (top and right panels) first received inhibitory conditioning where a light (solid square) was paired with food but not when compounded with the tone (open square) or when the tone occurred alone (solid circle), followed by two phases of excitatory conditioning with tone, where the tone was paired with food. The final phase of that conditioning is shown at right. Rats in Group EIE (bottom and right panels) were treated as were rats in Group IEE, but the first two phases were reversed. Responding to the tone is represented by the solid triangle.

effects of context $\left[F(1,14)=4.97, p=.04, \eta_{\mathrm{p}}^{2}=.26\right]$, session $\left[F(1,14)=25.79, p<.001, \eta_{\mathrm{p}}^{2}=.65\right]$, and trial $\left[F(5,70)=10.94, p<.001, \eta_{\mathrm{p}}^{2}=.44\right]$. The same analysis of responding in the pre-CS showed only an effect of trial $\left[F(5,70)=4.05, p=.003, \eta_{\mathrm{p}}^{2}=.22\right]$. Responding in the pre-CS averaged 2.13 at the first trial in a session and .63 on the final trial.

Simple-effect tests of responding in the CS confirmed that the effect of context was roughly comparable between groups on a trial-by-trial basis, as indicated by the overall analysis. In Group IEE, there were effects on Trials 2 and 4 of Session $1\left[F_{\mathrm{s}}(1,50) \geq 11.12, p \mathrm{~s} \leq .002\right.$, $d \mathrm{~s} \geq .72]$ and on Trials 1 and 3 of Session $2\left[F_{\mathrm{s}}(1,50) \geq\right.$ $4.72, p \mathrm{~s} \leq .035, d \mathrm{~s} \geq .92]$. In Group EIE, there were effects on Trials 2,3 , and 4 of Session $1[F \mathrm{~s}(1,50) \geq 4.72$, $p \mathrm{~s} \leq .035, d \mathrm{~s} \geq .57]$.

The possibility that responding, which underwent extinction in the first session, could show recovery between sessions was not initially considered when the experiment was planned; yet some recovery was evident. Compari- sons of responding at the end of the first test session with that at the beginning of the second session revealed recovery in Group IEE when tested in Context $\mathrm{A}[F(1,74)=$ $8.64, p=.004, d=1.02]$. There was no such effect in Context $\mathrm{B}$, nor in either context in Group EIE $[F \mathrm{~s}(1,74) \leq$ $1.34, p s \geq .25]$.

Replication 2. Data from the second replication are shown in the right-hand part of Figure 4. The eight trials in each session of testing in each context were analyzed with a group $\times$ context $\times$ trials $\times$ session ANOVA. Of most importance, there was an effect of context $[F(1,14)=$ $\left.7.35, p=.017, \eta_{\mathrm{p}}^{2}=.34\right]$. There was also an effect of session $\left[F(1,14)=24.22, p<.001, \eta_{\mathrm{p}}^{2}=.63\right]$. No other effects were reliable, although the context $\times$ session interaction approached reliability $[F(1,14)=3.44, p=.08]$. The same analysis applied to responding in the pre-CS produced no reliable effects $(p s>.07)$ aside from an effect of session $[F(1,14)=4.97, p=.04]$. There was somewhat less pre-CS responding in the second session $(M=$ 1.66) than in the first $(M=3.29)$. 

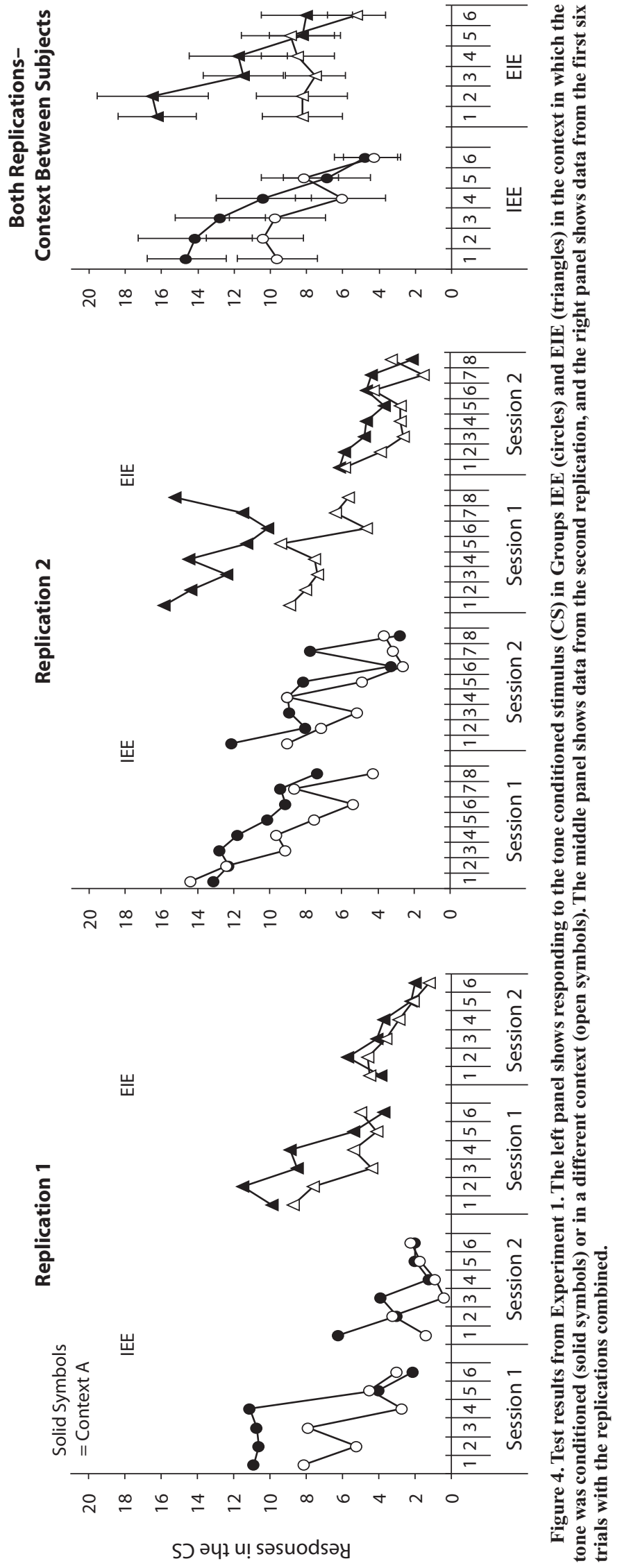
Simple-effect tests of responding in the CS showed only one detectable effect of context on a trial-by-trial basis in Group IEE; this occurred on the seventh trial of the second session $[F(1,49)=5.30, p=.026, d=.84]$. In Group EIE, reliable context effects were observed on Trials $1-4$ and 6-8 of the first session $[F \mathrm{~s}(1,49) \geq 6.20, p \mathrm{~s} \leq .001, d \mathrm{~s} \geq .75]$.

As with the first replication, there was some recovery of extinguished responding between sessions in Group IEE in both contexts $[F \mathrm{~s}(1,91) \geq 7.97, p \mathrm{~s} \leq .006, d \mathrm{~s} \geq .56]$. There was no recovery in Group EIE, where responding in Context A decreased between sessions $[F(1,91)=29.42, p<$ $.001, d=1]$ and did not change in Context $\mathrm{B}(F<1)$.

Replications combined. The first six trials of Session 1 were not confounded between replications by the extra two trials in each session that occurred in the second replication. Thus, to further characterize the overall test results, I compared rats who received their first six trials of testing in Context A with those that received their first six trials in Context B in each group, collapsed across replication, in a group $\times$ context $\times$ trials $\times$ replication ANOVA. (These data are shown at the far right of Figure 4.) The analysis showed a significant effect of trials $[F(5,120)=$ $\left.10.95, p<.001, \eta_{\mathrm{p}}^{2}=.31\right]$ and a trials $\times$ context interaction $\left[F(5,120)=3.14, p=.01, \eta_{\mathrm{p}}^{2}=.12\right]$, where the context effect appeared evident in both groups in the early trials. No other effects were reliable, though the main effects of context and replication approached reliability $[F \mathbf{s}(1,24)=$ $3.73, p=.065$, and 4.24, $p=.05$, respectively].

\section{Discussion}

In Experiment 1, excitatory conditioned responding to a tone was lost when the tone was tested in a context in which it had not been trained. In Group EIE, the tone had first been paired with food to establish an excitatory tone $\rightarrow$ food association; it then underwent a phase of inhibitory conditioning, where it was used in a conditioned inhibition design to signal the absence of food. In Group IEE, the tone first underwent a phase of inhibitory conditioning prior to excitatory conditioning. In both groups, the tone underwent excitatory conditioning in the final excitatory conditioning phase. Thus, at test, the tone in Group EIE was ambiguous, in that it could control two associations and was currently expressing an excitatory association consistent with what was first learned about the tone. In Group IEE, the tone was similarly ambiguous, but it was expressing an excitatory association consistent with what was learned second about the tone. If second-learned information was more affected by a context switch than that learned first, as Nelson (2002) suggested, a larger effect of context would have been seen in Group IEE than in Group EIE.

The results show a general main effect of context in both groups, suggesting that excitation was equally affected by a context change in the two conditions. Such differences in sensitivity to context changes as existed between the groups contradicted what Nelson (2002) had suggested; that is, the trend was toward the context effect in Group EIE being larger than in Group IEE. Such a pattern would suggest that the proximity of the inhibi- tory conditioning phase to the test could have affected the context-switch result; that inhibition might be more accessible when acquired in temporal proximity to the test and thus produce a slightly bigger effect of a context change. Consistent with that hypothesis, some responding extinguished during the first session of testing tended to recover in the second session in Group IEE, but not in Group EIE, where inhibition may have been more accessible.

It might be argued that the multiple phases of training were not responsible for the context specificity of responding obtained in these studies. Rather, it could be said that the responding observed with this method and equipment might be context specific, whether multiple phases of training were conducted or not. As mentioned earlier, there are good reasons, however, to reject the suggestion that the conditioning established in the final phase of this experiment would show context dependency in the absence of the previous phases. First, there are many previous studies showing that context effects on this type of responding with CSs that have only been paired with food are not observed with procedures and equipment nearly identical to those presented here (e.g., Bouton \& Nelson, 1994; Brooks \& Bouton, 1994; Nelson, 2002; Nelson \& Bouton, 1997). With appetitive conditioning using different equipment and procedures, no loss has been observed when, as in the present experiments, extensive conditioning was conducted (Maes, Havermans, \& Vossen, 2000). Moreover, in Experiment 2, context change increased rather than decreased responding; the change in context does not, therefore, cause any general response deficit.

\section{EXPERIMENT 2}

Experiment 2 compared the context specificity of firstand second-learned inhibition between groups for which the ambiguity of the stimuli was equated. The design is shown in the bottom half of Figure 1. Rats first underwent simple conditioning with a light, and then two groups were matched in their performance on this task. The groups underwent three phases of training with a tone, as in Experiment 1 , but the final phase was inhibitory conditioning. In Group EII, rats first underwent excitatory conditioning with the tone, followed by two phases of inhibitory conditioning. In Group IEI, rats first underwent inhibitory conditioning, then excitatory conditioning, followed by the final phase of inhibitory conditioning. At test, the groups had undergone the same amounts of excitatory and inhibitory conditioning with the tone, with manipulation occurring only to the order in which those associations were acquired. The test generally followed the procedure of Nelson (2002), in which all subjects experienced the tone paired with food in each context; this constituted a retardation test allowing a within-subjects test of the effects of context, as in Experiment 1.

If second-learned associations are more contextually controlled than first learned ones are, as indicated by the work of Nelson (2002), there should be less inhibi- 
tion in Context B than in Context A, and this loss should be bigger in Group EII than in Group IEI. Experiment 1 suggests, however, that when stimuli are equally ambiguous, the order in which the associations were learned has little impact on contextual control. Both first- and secondlearned associations seem to be under the control of context to a certain extent. If a symmetrical result should be obtained with inhibitory learning, an increase in responding should be observed with a context change, and that increase would be roughly equal between conditions.

\section{Method}

\section{Subjects and Apparatus}

Sixteen female Wistar rats served as subjects in each of two identical replications. Conditions were the same as in the previous study. The same apparatus used in Experiment 1 was used in Experiment 2.

\section{Procedure}

All rats were run in four daily 1-h sessions (two in Context A, two in Context B), in the same manner as in Experiment 1. For every session in Context $\mathrm{A}$, a corresponding session was conducted in Context $\mathrm{B}$, where $\mathrm{F}$ was paired with food at the same time into the session as that at which food occurred in Context $\mathrm{A}$. The experiment was conducted in two identical replications, with 16 rats in each replication ( 8 per group). The design is shown in the lower portion of Figure 2. To ensure group equivalence, all rats first underwent initial $\mathrm{L}$ conditioning and two matched groups were formed using the resulting data. Rats in Group IEI first underwent inhibitory conditioning, then excitatory conditioning, and then inhibitory conditioning, final phase. Rats in Group EII first underwent excitatory conditioning, then inhibitory conditioning, then inhibitory conditioning, final phase.

Initial L conditioning. There were four sessions of conditioning with $\mathrm{L}$ in Context $\mathrm{A}$. There were 12 pairings of $\mathrm{L}$ with the US in each session with a variable ITI $(M=270 \mathrm{sec})$.

Inhibitory conditioning. Inhibitory conditioning began with 2 sessions of $\mathrm{L}+$ training as in the initial L conditioning phase. The next 10 sessions of conditioned inhibition training contained $4 \mathrm{~L}+$ trials, $2 \mathrm{~T}$ - trials, and 12 trials of $\mathrm{L}$ and $\mathrm{T}$ combined simultaneously without the US. Arrangement of the stimulus sequences was the same as in the previous experiment.

Excitatory conditioning. There were 10 sessions of excitatory conditioning with sessions conducted exactly as in the excitatory conditioning phase of the previous experiment.

Inhibitory conditioning, final phase. The final phase of inhibitory conditioning contained 10 sessions conducted in the same way as those in the inhibitory conditioning phase. There were no initial $\mathrm{L}+$ training sessions in this phase.

Testing. All rats received two 30-min sessions of testing in each context. Half of the rats in each group were tested in the sequence $\mathrm{ABAB}$, and the other half with the opposite order. During the 30-min test sessions, rats received eight trials where $\mathrm{T}$ was paired with food with a variable ITI $(M=195 \mathrm{sec})$.
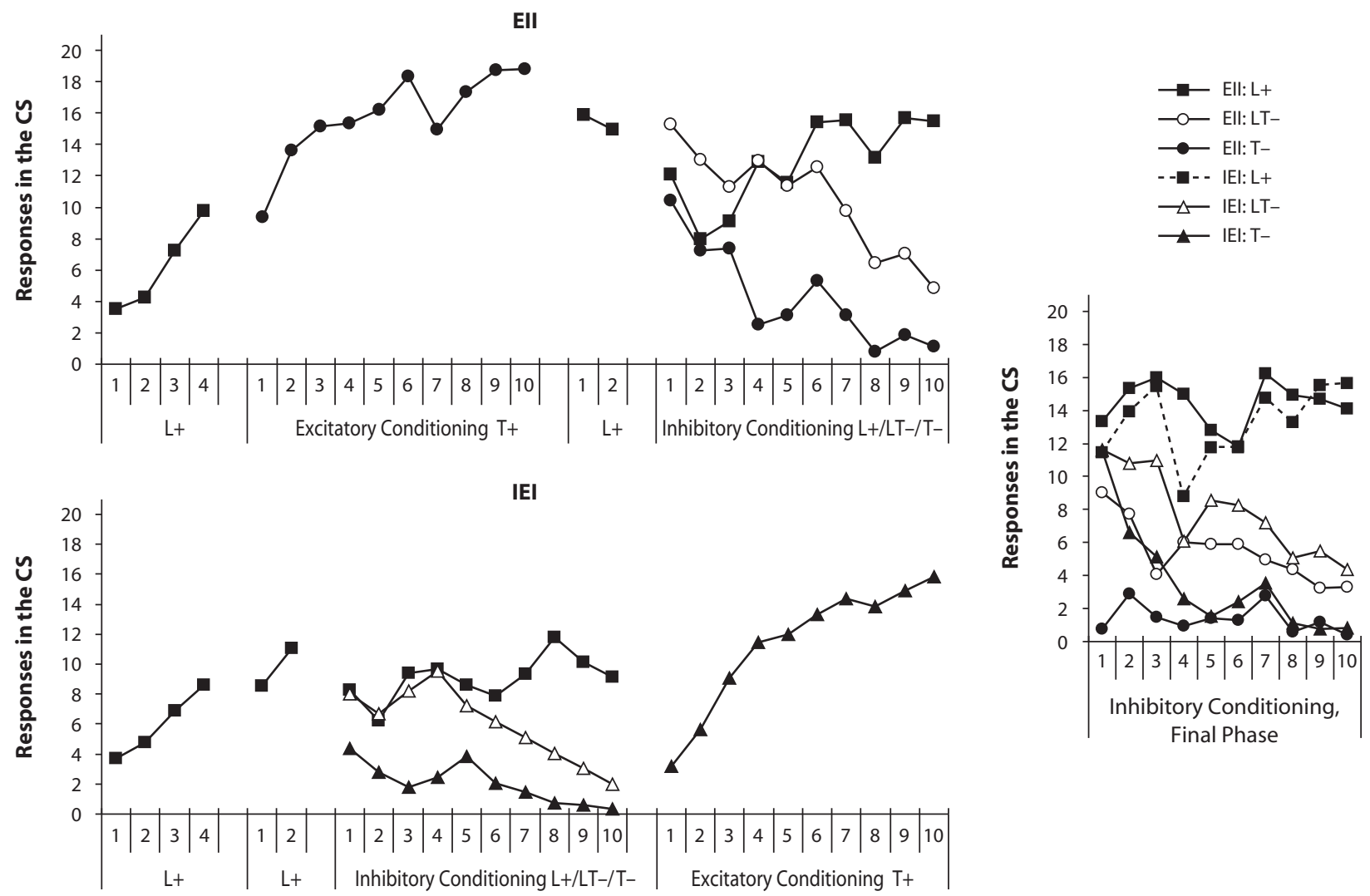

Figure 5. Results of inhibitory and excitatory conditioning with a tone conditioned stimulus (CS) from Experiment 2. All rats first received excitatory conditioning where a light was paired with food (solid squares). Rats in Group EII (top and right panels) then received excitatory conditioning where a tone was paired with food followed by two phases of inhibitory conditioning where the light was paired with food but not when compounded with the tone (open square) or when the tone occurred alone (solid circle). The final phase of that conditioning is shown at right. Rats in Group IEI (bottom and right panels) were treated as were rats in Group IEE but the first two phases were reversed. Responding to the tone is represented by the solid triangle. 
Data analysis. Data were collected and analyzed as in Experiment 1 .

\section{Results}

Data from the initial L conditioning phase and the first two phases of training are shown in the left and middle portions of Figure 5. The top panel shows the results from Group EII and the bottom shows the results from Group IEI. The patterns shown in the figure were clearly evident in both replications, and replication was not included in the analyses until the analysis of the test data. Groups were compared directly only during those phases of training in which they received identical treatment at the same time.

Initial $\mathrm{L}$ conditioning. Initial $\mathrm{L}$ conditioning is shown at the far left in the top and bottom panels of Figure 4. A group $\times$ session ANOVA showed that responding increased over sessions $\left[F(3,90)=31.61, p<.001, \eta_{\mathrm{p}}^{2}=\right.$ $.51]$. Since the groups were matched on these data, there was no effect of group and no interaction $(F \mathrm{~s}<1)$. The next two phases were analyzed within each group beginning with Group EIE. Analyses followed the data in Figure 5 from left to right.

\section{Group EII}

Excitatory conditioning. Responding to $\mathrm{T}$ increased over sessions $\left[F(9,135)=10.90, p<.001, \eta_{\mathrm{p}}^{2}=.42\right]$.

Inhibitory conditioning. Responding during the first two $\mathrm{L}+$ sessions of this phase remained high and did not change between sessions $(F<1)$. During the discrimination portion of the phase, responding to L increased slightly; responding to LT and T decreased over sessions, as indicated by a stimulus $\times$ session interaction $[F(18,270)=14.44$, $\left.p<.001, \eta_{\mathrm{p}}^{2}=.49\right]$. Simple effects of session were reliable for each stimulus $[F \mathrm{~s}(9,378) \geq 8.94]$.

\section{Group IEI}

Inhibitory conditioning. Responding during the first two L + sessions of the inhibitory conditioning phase was high, and increased between sessions $[F(1,15)=12.83$, $\left.p=.003, \eta_{\mathrm{p}}^{2}=.46\right]$. During the discrimination portion of the phase responding to $\mathrm{T}$ did not change, whereas responding to L did, and responding to LT decreased, as evidenced by a significant stimulus $\times$ session interaction $\left[F(18,270)=7.22, p<.001, \eta_{\mathrm{p}}^{2}=.32\right]$. There were effects of session on responding to both L and LT $[F \mathrm{~s}(9,326) \geq$ 3.2], but not to $\mathrm{T}(F<1)$.

Excitatory conditioning. Responding to $\mathrm{T}$ during the 10 excitatory conditioning sessions increased over sessions $\left[F(9,135)=16.62, p<.001, \eta_{\mathrm{p}}^{2}=.53\right]$.

\section{Inhibitory Conditioning, Final Phase}

The two groups were compared during inhibitory conditioning, final phase, and the data are shown in the right-hand side of Figure 5. A hard-drive failure prevented retrieval and analysis of the data from this phase in the second replication. Thus, only the data from the first replication were presented and analyzed here. Although not removed and analyzed on a daily basis, the data from the second replication were inspected daily and the patterns evident in the right-hand side of Figure 5 were evident in the second replication.

The data were analyzed with a group $\times$ stimulus $\times$ session ANOVA. Responding to L remained high during the session, but responding to $\mathrm{T}$ and LT decreased over sessions at a different rate between groups as evidenced by a significant group $\times$ stimulus $\times$ session interaction $\left[F(18,252)=2.98, p<.001, \eta_{\mathrm{p}}^{2}=.17\right]$.

The groups were compared in their responses to $\mathrm{T}$ and the ability of $\mathrm{T}$ to suppress responding to L. Responding to $\mathrm{T}$ was significantly higher on the first session in Group IEI $[F(1,25)=16.83, p<.001, d=2.19]$. Responding to $\mathrm{T}$ did not differ between groups on any other session $[F \mathrm{~s}(1,25) \leq 2.09, p \mathrm{~s} \geq .17]$. In Group EII, T reliably suppressed responding to $\mathrm{L}$ throughout the phase $\left[F_{\mathrm{s}}(1,78) \geq 4.51, p \mathrm{~s} \leq .03, d \mathrm{~s} \geq 1.13\right]$. In Group IEI, T suppressed responding to $\mathrm{L}$ on Session $3[F(1,78)=4.8$, $p=.003, d=1.17]$ and Sessions $6-10\left[F_{\mathrm{s}}(1,78) \geq 13.81\right.$, $p \mathrm{~s}<.001, d \mathrm{~s} \geq 1.99]$.

The same analysis of responding in the pre-CS produced a stimulus $\times$ session interaction $[F(18,252)=1.65, p=$ .049] that ultimately did not affect the interpretation of responding in the CS. Responding prior to L averaged 1.60 and responding to LT averaged 1.54 overall. Responding prior to $\mathrm{T}$ was somewhat higher on Session $3(M=3.06)$ than responding prior to $\mathrm{LT}(M=1.75)[F(1,379)=4.50$, $p=.03]$. Responding prior to $\mathrm{T}$ on Session $7(M=4.09)$ was somewhat higher than responding prior to both LT $(M=1.56)$ and $\mathrm{L}(M=1.64)[F \mathrm{~s}(1,379) \geq 15.14, p \mathrm{~s} \leq$ $.001]$. Responding prior to $\mathrm{T}$ on the remaining sessions averaged 1.41 .

\section{Test}

Responding during the test is shown in Figure 6. Data were analyzed with a context $\times$ group $\times$ session $\times$ trials $\times$ replication ANOVA. The analysis showed several effects: group $[F(1,28)=17.03]$, session $[F(1,28)=$ $21.85]$, trials $[F(7,196)=7.12]$, and session $\times$ trials $[F(7,196)=3.64]$. The effects of most relevance for the present work were the significant effects of context $\left[F(1,28)=11.23, p=.002, \eta_{\mathrm{p}}^{2}=.29\right]$, the context $\times$ trials $\times$ group interaction $[F(7,196)=2.56, p=.02$, $\left.\eta_{\mathrm{p}}^{2}=.08\right]$, and a context $\times$ trials $\times$ replication interaction $\left[F(7,196)=2.41, p=.02, \eta_{\mathrm{p}}^{2}=.08\right]$. The interaction of context $\times$ trials $\times$ group with session approached reliability $[F(7,196)=1.78, p=.09]$.

Before discussing the more interesting effects, I will first dispense with the context $\times$ trials $\times$ replication interaction. Collapsing across sessions and groups, the effect of context in the first replication appeared most prevalent during the middle trials $(3,4,5)$, which averaged 9.65 and 14.35 in Contexts A and B, respectively. In the second replication, the effect of Context appeared most prevalent during the last three trials, which averaged 8.03 and 12.80 in Contexts A and B, respectively. Simple effects of replication on each trial in each context collapsed across sessions failed to detect any significant differences between the replications $[F \mathrm{~s}(1,40)<1.88]$.

As shown in Figure 6, the context effect appeared to be present in each group, but less so in the second session. 


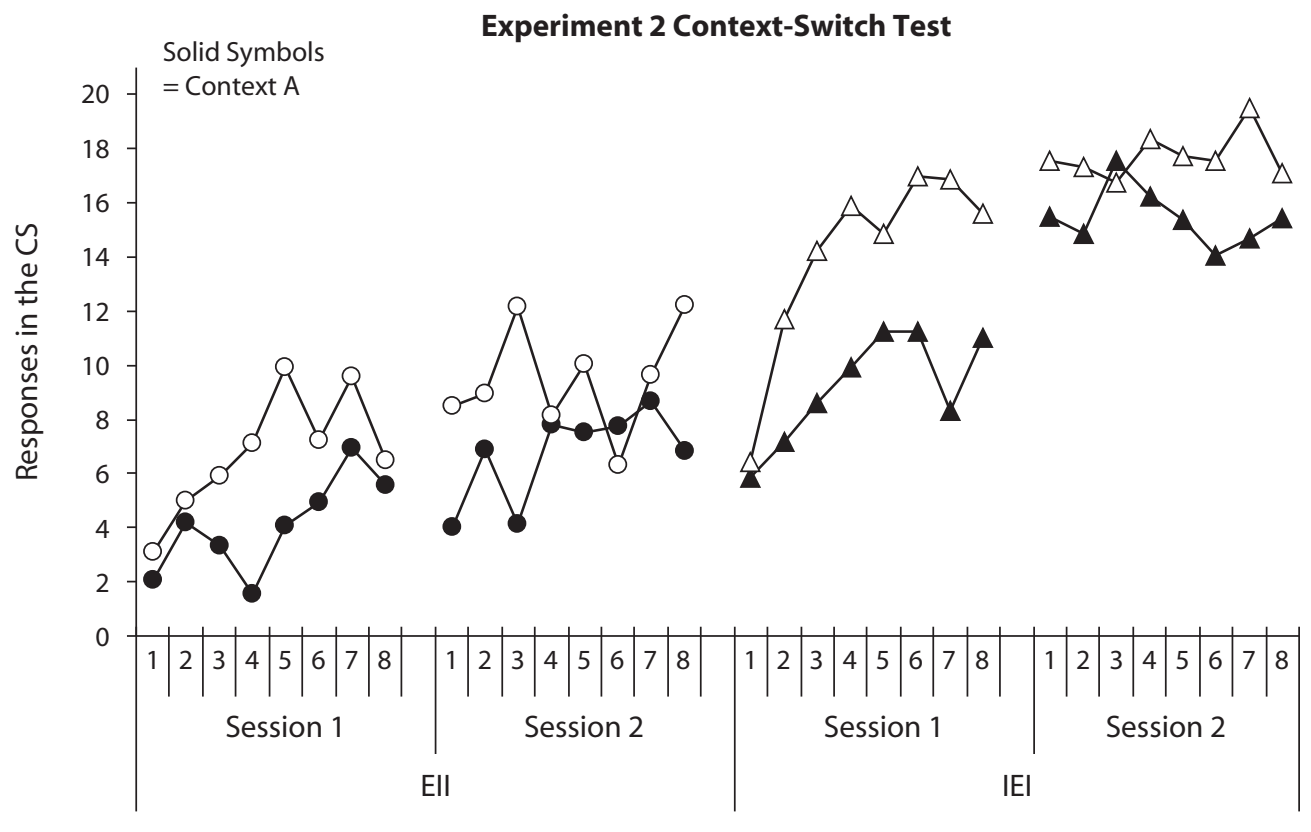

Figure 6. Test results from Experiment 2. Panels show responding to the tone conditioned stimulus (CS) as it was paired with food in the context where it was conditioned (solid circles) or in a different context (open circles). The left panel shows responding in Group EII, and the right panel shows responding in Group IEI.

Simple-effect tests of context on each trial within each group largely confirmed what is shown in the figure and overall analysis. In Group EII there were effects of context on Trials 4 and 5 of the first session and Trials 3 and 8 of the second session $[F \mathrm{~s}(1,84) \geq 4.54, p \mathrm{~s} \leq .03, d \mathrm{~s} \geq$ .796]. In Group IEI the effect of context was evident on Trials $3,4,6$, and 7 of the first session $\left[F_{\mathrm{s}}(1,84) \geq 4.86\right.$, $p \mathrm{~s} \leq .03, d \mathrm{~s} \geq .805]$. There were no significant effects in the second session $[F \mathrm{~s}(1,84)<3.65, p \mathrm{~s} \geq .06$ (Trial 7)].

Experiment 1 demonstrated recovery between the last trial of the first session and the first trial of the second session. No such effect was observed here. There was no change between sessions in either context in Group EIE $\left(F_{\mathrm{S}}<1\right)$. In Group IEI there was no change in Context $\mathrm{B}(F<1)$, and none in Context $\mathrm{A}[F(1,104)=3.63, p=.059]$.

The same overall analysis of the responding in the preCS produced a session $\times$ context $\times$ trial $\times$ replication interaction $[F(7,196)=3.40, p=.002]$ that superseded any other main effect or interaction in the analysis. Simple effect tests of context (collapsed across group) were conducted on each trial in each session in each replication. The interaction was due to two different trials in Context $\mathrm{A}$, where responding was high in different sessions between the replications. Omitting the outlying response rates reported next, pre-CS responding was low and averaged 3.44 in the first replication and 4.36 in the second. In the first replication there was a high response rate in Context $\mathrm{A}$ in the second session on the sixth trial $(M=11.14)$ that was higher than the corresponding rate in Context $\mathrm{B}$ $(M=2.44)[F(1,131)=16.23]$. In the second replication there was a high response rate in Context $\mathrm{A}$, but it was in the first session on the fourth trial $(M=8.81)$ and was higher than the corresponding rate in Context $\mathrm{B}(M=$ $2.25)$. No other comparisons were reliable $[F \mathrm{~s}(1,131) \leq$ $2.92, p \mathrm{~s} \geq .09]$.

\section{Discussion}

Experiment 2 was designed to assess the impact of a context change on first- and second-learned inhibition in equally ambiguous stimuli. Each group underwent three phases of training, ending with a final inhibitory conditioning phase. For Group EII, this phase was consistent with what the animals had learned second about the tone. In the first phase, the tone was made an excitor for food, and then made an inhibitor in the second phase. For Group IEI, the final phase was consistent with what was learned first about the tone. In the first phase, the tone was made an inhibitor for food (see Bouton \& Nelson, 1994, for the results of summation tests from this procedure), then made an excitor.

The hypothesis predicted that there would be a larger effect of a context change in Group EII for which inhibition was the second-learned association. The only support for the hypothesis comes from the second session of testing where there was an effect of context in Group EII, but none that could be statistically detected in Group IEI, a result in favor of the hypothesis. However, it is likely that a ceiling effect occluded any context-switch effect on the second session in Group IEI. On the first session, where responding was well below a ceiling in both groups, there was an effect of context in both groups. Reacquisition of excitatory responding was more rapid in Context $\mathrm{B}$, where the stimulus had never before been presented, than in Context A, where training took place. Simple effect tests were, as in Experi- 
ment 1, suggestive that the effect of context was larger in Group IEI than in Group EII, which was exactly opposite to what was predicted by the initial hypothesis. However, as in Experiment 1, the overall pattern of evidence did not allow a strong conclusion regarding group differences.

\section{GENERAL DISCUSSION}

In the present set of studies, the effect of a context switch was assessed on first- and second-learned information in equally ambiguous stimuli. In each experiment, multiple associations were conditioned to a tone CS over three phases. In experimental groups (Groups IEE and EII from Experiments 1 and 2, respectively), the final phase of conditioning was different from the first, and thus the final association being expressed at the time of test was consistent with what was second learned about the stimulus. In control conditions (Groups EIE and IEI from Experiments 1 and 2, respectively), the final phase was the same as the first, so the final association being expressed at the time of test was consistent with what was first learned about the stimulus.

In both studies, there were main effects of context on the test. Responding controlled by the association established in the final phase of training was attenuated with a context change. In Experiment 1, where the responding was under the influence of excitation, there was a loss of responding with a context switch. In Experiment 2, where the responding was under the influence of inhibition, there was an increase in responding. The context switch effect attenuated the influence of the most recent training.

The results provide no evidence that second-learned associations are more context-specific than are those learned first. Rescorla (2001) suggested that when a stimulus undergoes retraining, as did Groups EIE and IEI, new learning may occur to the extent that the original training is not recovered. From that perspective, the final excitation accrued in EIE could be something other than firstlearned information, as would be the inhibition accrued in the third phase in Group IEI. Under this interpretation, no effect of a change in context would necessarily be expected. Losses of second-learned excitation in Group EIE, for example, should be offset by losses in second-learned inhibition. Overall, the results are not supportive in any way of the idea that context specificity favored secondlearned information simply because it was learned after the acquisition of some other association.

The findings are consistent with ideas put forth by Rosas, García-Gutiérrez, and Callejas-Aguilera (2006) that attention is aroused to the context when a CS undergoes training that produces ambiguity. According to them, once the CSs become ambiguous in the second phase of training, attention to the context is aroused and all subsequent learning should become context specific.

A recent report by Nelson and Callejas-Aguilera (2007) also bears on these results. Nelson and Callejas-Aguilera conducted a series of studies with humans which demonstrated that the quality of an association being second learned has no real impact on contextual control, aside from the interference produced when the second association was acquired. For example, participants first learned that a particular cue (e.g., a garden product) predicted a particular outcome (e.g., flowers growing) in the first phase of a study. In the second phase, the cue was either paired with the first outcome and a new one (e.g., a garden product that produced flowers now leads to flowers and bugs), or with just the new one (e.g., a garden product that once led to flowers now leads only to bugs). In the first condition, information about the cue and the new outcome was the second type of information learned about the cue, but it did not interfere with the information acquired between the cue and the first outcome. In the second condition, information about the cue and the outcome was the second type of information learned about the cue, and it did interfere with the previous learning. When these conditions were tested in a different context, learning about the cue and the new outcome was lost only in the latter condition.

On the basis of that result, Nelson and Callejas-Aguilera (2007) concluded that it is not enough for a cue to acquire a second association to produce contextual control. Rather, contextual control is triggered by the interference produced when a cue acquires a new meaning that conflicts with an earlier one. In the present studies, the final associative valence of the tone was opposite to a previous valence in both groups in both of the present studies. Thus, the acquisition of that valence should produce interference leading to its context specificity, whether that valence had been acquired previously, as in Groups EIE and IEI, or not.

The results of these two experiments in isolation would be predicted by models of learning that allow for configurations of CSs and the contexts in which they occur to control performance, such as those of Pearce (1994) and Wagner (2003). The underlying associations that control responding elicited by the tone would depend, in part, on a representation itself dependent on the joint occurrence of the tone and the context. Testing of the tone outside that context would result in an attenuation of the controlling representation, and thus a loss in the response potential. The only shortcoming of these models is their inability to account for cases where simple conditioning, either excitatory or inhibitory, is unaffected by context change (e.g., Nelson, 2002). The models do not predict that the effect of context would be more apparent after acquiring multiple associations to the stimuli.

The findings show that when multiple associations were conditioned to a stimulus across phases, those associations learned later became context specific, whether or not they were consistent with what was first learned about the stimuli. The most recent information acquired to a stimulus that controls multiple associations was that which was most affected by a context change. There was no support for the simple hypothesis that contextual control favors second learning. Rather, the findings provide better support for the idea that interference produced by the changing contingencies across phases contributes to subsequent contextual control, whether or not that learning is consistent with earlier learning. 


\section{AUTHOR NOTE}

This research was made possible by Grant R15 MH65249-01A2 from the National Institutes of Health, and a Ramon y Cajal Fellowship awarded to the author by the Spanish Ministry of Science, Culture and Sport, which was funded in part by the Fondo Social Europeo. I thank Cody Brooks of Denison University, Juan Manuel Rosas of the University of Jaen, and Steven Glautier of the University of Southampton for their comments on early versions of the manuscript, as well as Jose Callejas-Aguilera at the University of Jaen for his assistance in the conduct of the second replication of the first study. Correspondence concerning this article should be addressed to J. B. Nelson, Dept. Processos Basicos y Desarrollo, Universidad de Pais Vasco, Avenida de Tolosa 70, San Sebastian, Spain 20018 (e-mail: jamesbyron.nelson@ehu.es).

\section{REFERENCES}

Bonardi, C., Honey, R. C., \& Hall, G. (1990). Context specificity of conditioning in flavor-aversion learning: Extinction and blocking tests. Animal Learning \& Behavior, 18, 229-237.

Bouton, M. E. (1993). Context, time, and memory retrieval in the in terference paradigms of Pavlovian learning. Psychological Bulletin, 114, 80-99.

Bouton, M. E. (1994a). Conditioning, remembering, and forgetting Journal of Experimental Psychology: Animal Behavior Processes, 20, 219-231.

Bouton, M. E. (1994b). Context, ambiguity, and classical conditioning. Current Directions in Psychological Science, 3, 49-53.

Bouton, M. E. (1997). Signals for whether versus when an event will occur. In M. S. Fanselow \& M. E. Bouton (Eds.), Learning, motivation, and cognition: The functional behaviorism of Robert C. Bolles (pp. 385409). Washington, DC: American Psychological Association.

Bouton, M. E., \& Bolles, R. C. (1979). Contextual control of the extinction of conditioned fear. Learning \& Motivation, 10, 445-466.

Bouton, M. E., \& KING, D. A. (1983). Contextual control of the extinction of conditioned fear: Tests for the associative value of the context Journal of Experimental Psychology: Animal Behavior Processes, 9, 248-265.

Bouton, M. E., Mineka, S., \& Barlow, D. H. (2001). A modern learning theory perspective on the etiology of panic disorder. Psychological Review, 108, 4-32.

Bouton, M. E., \& Nelson, J. B. (1994). Context-specificity of target versus feature inhibition in a feature-negative discrimination. Journal of Experimental Psychology: Animal Behavior Processes, 20, 51-65.

Brooks, D. C., \& Bouton, M. E. (1994). A retrieval cue for extinction attenuates response recovery (renewal) caused by a return to the conditioning context. Journal of Experimental Psychology: Animal Behavior Processes, 20, 366-379.

Estes, W. K. (1976). Structural aspects of associative models of memory. In C. N. Cofer (Ed.), The structure of human memory (pp. 31-53) San Francisco: Freeman.

Hall, G., \& Honey, R. C. (1989). Contextual effects in conditioning, latent inhibition, and habituation: Associative and retrieval functions of contextual cues. Journal of Experimental Psychology: Animal Behavior Processes, 15, 232-241.
Hall, G., \& Honey, R. C. (1990). Context-specific conditioning in the conditioned-emotional-response procedure. Journal of Experimental Psychology: Animal Behavior Processes, 16, 271-278.

Havermans, R. C., Keuker, J., Lataster, T., \& Jansen, A. (2005). Contextual control of extinguished conditioned performance in humans. Learning \& Motivation, 36, 1-19.

Honey, R. C., Willis, A., \& Hall, G. (1990). Context specificity in pigeon autoshaping. Learning \& Motivation, 21, 125-136.

Howell, D. C. (1987). Statistical methods for psychology. Boston: Duxbury Press.

Kaye, H., \& Mackintosh, N. J. (1990). A change of context can enhance performance of an aversive but not of an appetitive conditioned response. Quarterly Journal of Experimental Psychology, 42B, 113-134.

Maes, J. H. R., Havermans, R. C., \& Vossen, J. M. H. (2000). Factors affecting context specificity of appetitive conditioned responding. Behavioural Processes, 48, 149-157.

Mineka, S., Mystkowski, J. L., Hladek, D., \& Rodriguez, B. I. (1999). The effects of changing contexts on return of fear following exposure therapy for spider fear. Journal of Consulting \& Clinical Psychology, 67, 599-604

NeLson, J. B. (2002). Context specificity of excitation and inhibition in ambiguous stimuli. Learning \& Motivation, 33, 284-310.

Nelson, J. B., \& Bouton, M. E. (1997). The effects of a context switch following serial and simultaneous feature-negative discriminations. Learning \& Motivation, 28, 56-84.

Nelson, J. B., \& Callejas-Aguilera, J. E. (2007). The role of interference produced by conflicting associations in contextual control. Journal of Experimental Psychology: Animal Behavior Processes, 33, 314-326.

Pearce, J. M. (1994). Similarity and discrimination: A selective review and a connectionist model. Psychological Review, 101, 587-607.

ResCorla, R. A. (2001). Retraining of extinguished Pavlovian stimuli. Journal of Experimental Psychology: Animal Behavior Processes, 27, 115-124.

Rosas, J. M., García-Gutiérrez, A., \& Callejas-Aguilera, J. E. (2006). Effects of context change upon retrieval of first and secondlearned information in human predictive learning. Psicológica, 27, 35-56.

Satterthwaite, F. E. (1946). An approximate distribution of the estimates of variance components. Biometrics Bulletin, 2, 110-114.

WAGNER, A. R. (1981). SOP: A model of automatic memory processing in animal behavior. In N. E. Spear \& R. R. Miller (Eds.), Information processing in animals: Memory mechanisms (pp. 5-47). Hillsdale, NJ: Erlbaum.

WaGner, A. R. (2003). Context-sensitive elemental theory. Quarterly Journal of Experimental Psychology, 56B, 7-29.

Welch, B. L. (1937). The significance of the difference between two means when the population variances are unequal. Biometrika, 29, 350-362.

(Manuscript received August 13, 2008 revision accepted for publication September 5, 2008.) 